\title{
Non-small cell lung cancer treatment (r)evolution: ten years of advances and more to come
}

\author{
Luca Toschi, Sabrina Rossi, Giovanna Finocchiaro and Armando Santoro \\ Humanitas Research Hospital, Medical Oncology, Via Manzoni 56, 20089 Rozzano, Italy \\ Correspondence to: Luca Toschi. Email: luca.toschi@cancercenter.humanitas.it
}

\begin{abstract}
Diagnostic and treatment algorithms in non-small cell lung cancer (NSCLC) are evolving at a never-before-seen pace. Histological subtyping to maximise treatment efficacy and avoid toxicity has marked the beginning of the revolution, opening the way to molecular characterisation to guide genomically driven treatments with targeted agents, led by Epidermal Growth Factor Receptor (EGFR) and Anaplastic Lymphoma Kinase (ALK) inhibitors. More recently, agents against the Program Death 1 receptor (PD-1) and ligand 1 (PD-L1) have entered the clinical arena, offering new hope to NSCLC patients, although several uncertainties remain to be elucidated. Here, we review the most clinically relevant advances in the diagnosis and treatment of NSCLC in the past decade.
\end{abstract}

Keywords: non-small cell lung cancer (NSCLC), epidermal growth factor receptor (EGFR), anaplastic lymphoma kinase (ALK), program death 1 receptor $(P D-1)$, checkpoint inhibitors

ecancer 2017, 11:787 https://doi.org/10.3332/ecancer.2017.787

Copyright: (c) the authors; licensee ecancermedicalscience. This is an Open Access article distributed under the terms of the Creative Commons Attribution License (http://creativecommons.org/licenses/by/3.0), which permits unrestricted use, distribution, and reproduction in any medium, provided the original work is properly cited. 


\section{Introduction}

In 2002, the Eastern Oncology Cooperative Group (ECOG) published in the New England Journal of Medicine the results of a landmark randomised phase III trial comparing four chemotherapy platinum-based doublets in patients with untreated advanced non-small cell lung cancer (NSCLC) [1]. The rationale for conducting such a trial was to gain an insight into the efficacy of new, at that time, platinum partners, such as taxanes, gemcitabine and vinorelbine. The trial showed no overall survival (OS) difference between the four regimens, providing a clear take-home message for clinicians: in advanced NSCLC patients, any platinum-based doublet with third-generation agents can be used, with no need to refine patient selection based on clinical characteristics other than good performance status (ECOG PS 0-1).

In the past decade, treatment algorithms for NSCLC have dramatically evolved and are increasingly branching out as a result of better clinical and biological patient selection, availability of new agents (as indicated in Tables 1 and 2) and some amount of serendipity.

\section{Histology matters: lessons about toxicity and efficacy}

In the abovementioned ECOG trial, data on histology were not reported. In fact, in 2002, identification of NSCLC histological subtypes was considered irrelevant, with pathologists being required to discriminate only between NSCLC and small-cell lung cancer (SCLC), the latter following a peculiar treatment algorithm. The first hints suggesting that histological subclassification of NSCLC could play a key role in treatment decision emerged from a randomised phase II trial investigating the efficacy and safety of bevacizumab, a humanised monoclonal antibody directed against the vascular endothelial growth factor (VEGF), in combination with carboplatin and paclitaxel in patients with advanced NSCLC [2]. While the experimental arm showed promising signs of increased efficacy over chemotherapy alone, with improved response rate (RR), time-to-progression and OS, 6/66 (9\%) bevacizumab-treated patients experienced severe bleeding events, mostly hemoptysis, with four being fatal. Importantly, the increased bleeding risk was associated with squamous cell histology and this observation led to the subsequent development of bevacizumab exclusively in nonsquamous NSCLC. In another pivotal randomised phase III ECOG trial, the combination of carboplatin, paclitaxel and bevacizumab was compared with chemotherapy alone in a histologically selected population, with only nonsquamous NSCLC patients being included, and led to an impressive two-month improvement in OS, for the first time passing the 12-month mark [3]. Based on the results of this trial, the use of bevacizumab took hold in the United States, where carboplatin and paclitaxel was a commonly used chemotherapy regimen. In contrast, the AVAiL study failed to show an increased OS for bevacizumab in addition to cisplatin and gemcitabine [4], a popular chemotherapy regimen in Europe, somehow limiting bevacizumab use out of the United States. More recently, attempts have been made to redeem antiangiogenic agents in pretreated squamous cell NSCLC with contrasting results. On one hand, ramucirumab, a human IgG1 antiVEGFR2 monoclonal antibody, improved OS in combination with docetaxel in unselected NSCLC, including squamous cell histology, without increasing the incidence of severe bleeding events [5]. In contrast, the use of nintedanib in the same setting, while active in lung adenocarcinoma, failed to improve OS over single-agent docetaxel in patients with squamous cell cancer, albeit with no increased major bleeding toxicity [6].

Other clear signals about the crucial relevance of an accurate histological NSCLC characterisation came with the development of pemetrexed, an antifolate multitarget agent, which is currently used in the first- and second-line treatment of nonsquamous NSCLC. In the H3E-MC-JMDB, noninferiority phase III trial 1725 advanced NSCLC patients were randomised to cisplatin-gemcitabine or cisplatin-pemetrexed [7]. The trial met its primary endpoint of noninferior OS for the pemetrexed versus gemcitabine-based arm; however, subgroup analyses revealed differential activity of the two regimens based on histology. In fact, OS was significantly longer for cisplatin-pemetrexed versus cisplatin-gemcitabine in patients with adenocarcinoma (12.6 vs 10.9 months; HR $0.84, p=0.03)$ and large-cell carcinoma histology (10.4 vs 6.7 months; HR 0.67, p = 0.03). Conversely, in patients with squamous cell histology, OS was significantly improved with cisplatin-gemcitabine versus cisplatin-pemetrexed (10.8 vs 9.4 months; HR 1.24, p = 0.05). Similarly, a post hoc analysis conducted within a phase III trial of pemetrexed versus docetaxel as second-line treatment in unselected NSCLC showed the differential activity of the two agents according to histology [8], leading to pemetrexed approval and future development in nonsquamous tumours only. 
Table 1. FDA-approved targeted agents and angiogenesis inhibitors in NSCLC.

\begin{tabular}{|l|l|l|l|}
\hline \multicolumn{1}{|c|}{ Drug } & \multicolumn{1}{c|}{ Class } & Year & \multicolumn{1}{c|}{ Indication(s) } \\
\hline Bevacizumab & AntiVEGF monoclonal antibody & 2006 & In combination with carboplatin and paclitaxel, for metastatic nonsquamous NSCLC \\
\hline Erlotinib & First generation EGFR TKI & 2013 & EGFR-mutant (deletion exon 19 or L858R) advanced NSCLC \\
\hline Afatinib & Second generation EGFR TKI & 2013 & EGFR-mutant (deletion exon 19 or L858R) advanced NSCLC \\
\hline Ramucirumab & AntiVEGFR2 monoclonal antibody & 2014 & $\begin{array}{l}\text { In combination with docetaxel for the treatment of patients with metastatic NSCLC } \\
\text { progressing on or after platinum-based chemotherapy }\end{array}$ \\
\hline Ceritinib & Second generation ALK/ROS1 TKI & 2014 & ALK-rearranged advanced NSCLC progressing on or intolerant to crizotinib \\
\hline Necitumumab & AntiEGFR monoclonal antibody & 2015 & $\begin{array}{l}\text { In combination with gemcitabine and cisplatin for first-line treatment of metastatic } \\
\text { squamous NSCLC }\end{array}$ \\
\hline Gefitinib & First generation EGF TKI & 2015 & EGFR-mutant (deletion exon 19 or L858R) advanced NSCLC \\
\hline Osimertinib & Third generation EGFR TKI & 2015 & EGFR T790M+ advanced NSCLC progressing on or after EGFR TKI therapy \\
\hline Crizotinib & First generation ALK/ROS1 TKI & 2011 & $\begin{array}{l}\text { ALK-rearranged advanced NSCLC } \\
\text { ROS1-rearranged advanced NSCLC }\end{array}$ \\
\hline Alectinib & Second generation ALK TKI & 2015 & $\begin{array}{l}\text { ALK-rearranged advanced NSCLC progressing on or intolerant to crizotinib } \\
\text { First line ALK-rearranged advanced NSCLC }\end{array}$ \\
\hline Brigatinib & Second generation ALK TKI & 2017 & ALK-rearranged NSCLC progressing on or intolerant to crizotinib \\
\hline
\end{tabular}

VEGF: Vascular Endothelial Growth Factor

VEGFR2: Vascular Endothelial Growth Factor Receptor-2

EGFR: Epidermal Growth Factor Receptor

ALK: Anaplastic Lymphoma Kinase

ROS1: ROS Proto-oncogene-1

TKI: tyrosine kinase inhibitor

NSCLC: non-small cell lung cancer

Table 2. FDA-approved PD-1/PD-L1 inhibitors in NSCLC.

\begin{tabular}{|l|l|l|l|}
\hline \multicolumn{1}{|c|}{ Drug } & \multicolumn{1}{|c|}{ Class } & \multicolumn{1}{c|}{ Year } & \multicolumn{1}{c|}{ Indication(s) } \\
\hline Nivolumab & AntiPD-1 monoclonal antibody & 2015 & Metastatic NSCLC progressing on or after platinum-containing chemotherapy \\
\hline Pembrolizumab & AntiPD-1 monoclonal antibody & 2015 & $\begin{array}{l}\text { Metastatic PD-L1-expressing (TPS } \geq 1 \%) \text { NSCLC progressing on or after } \\
\text { platinum-containing chemotherapy }\end{array}$ \\
& 2016 & $\begin{array}{l}\text { Metastatic PD-L1-expressing (TPS } \geq 50 \%) \text { NSCLC, with no EGFR or ALK } \\
\text { genomic tumour aberrations, and no prior systemic chemotherapy treatment } \\
\text { for metastatic NSCLC }\end{array}$ \\
\hline Atezolizumab & AntiPD-L1 monoclonal antibody & 2016 & $\begin{array}{l}\text { Metastatic nonsquamous NSCLC in combination with pemetrexed and carbo- } \\
\text { platin, as first-line treatment }\end{array}$ \\
\hline
\end{tabular}

NSCLC: non-small cell lung cancer

TPS: tumour proportion score

EGFR: Epidermal Growth Factor Receptor

ALK: Anaplastic Lymphoma Kinase 
More recent examples of new agents developed in histologically selected NSCLC populations with different results include, among others, the antiepidermal growth factor receptor (EGFR) necitumumab. When added to cisplatin and pemetrexed in the phase III INSPIRE trial, which enrolled patients with nonsquamous histology only, necitumumab failed to prolong survival but increased toxicity, including serious adverse events [10]. In contrast, the SQUIRE trial, which investigated cisplatin and gemcitabine with or without necitumumab in squamous cell histology, met its primary endpoint of improved OS for the experimental arm (11.5 vs 9.9 months; HR 0.84, $p=0.01)$ [11]. A post hoc analysis showed that the benefit was limited to patients with some degree of EGFR protein expression assessed by immunohistochemistry (IHC) [12], leading to necitumumab approval by the US Food and Drug Administration (FDA) and European Medicines Agency (EMA) in EGFR-expressing squamous cell NSCLC.

Overall, the above-discussed data highlight the key role of histology in clinical practice and in the development of new agents, both for safety concerns and efficacy. As a result, the past decade has seen a progressive refinement of the diagnostic path in NSCLC, with massive efforts to obtain adequate samples for an accurate histological characterisation of the disease.

\section{Oncogene-addicted NSCLC: the quest for molecular targets}

Within the past several years, improvement of molecular biology techniques contributed to the identification of specific mutated oncogenes in NSCLC for which therapeutic treatments have either become commercially available or are under investigation, leading to a paradigm shift in the treatment of NSCLC. Therefore, appropriate tumour sampling is essential not only for histological subtyping but also for accurate tissue genotyping, as highlighted by the 'tissue is the issue' slogan coined few years ago.

\section{EGFR gene mutations}

Even before the crucial role of histology was established, the first clinically relevant molecular target in NSCLC was being identified, the EGFR gene mutations. If we look now at the major use of EGFR tyrosine kinase inhibitors (TKIs) in clinical practice, the whole EGFR story started with a fair amount of serendipity coupled with brilliant scientific intuitions from academic researchers. In fact, gefitinib and erlotinib - the first two oral EGFR TKIs to have reached the clinical arena - were initially investigated either alone or in combination with chemotherapy in unselected NSCLC populations based on the observation that the vast majority of lung tumour cells express EGFR on their surface [13]. Combination phase III trials of TKIs with platinum-based chemotherapy turned out negative for both drugs [14-17], while single-agent gefitinib showed some efficacy in terms of RR in the phase II IDEAL 1 and 2 trials [18, 19]. In 2003, the FDA approved gefitinib after chemotherapy failure in unselected NSCLC, but required a phase III trial to investigate gefitinib effect on survival - the ISEL study, which failed to show an OS improvement for gefitinib versus placebo [20] and led the FDA to withdraw its previous approval. However, in the years before FDA gefitinib registration, several patients could receive the drug within and expanded access programme, with clinicians observing major responses in a minority of patients, mostly women, nonsmokers and with adenocarcinoma. In the attempt of identifying the molecular bases underlying gefitinib activity in these subgroups, researchers sequenced EGFR exons in major responders, identifying what today are known as sensitising, not only to gefitinib but also to other TKls, mutations in the tyrosine kinase domain, with exon 19 deletions and the L858R point mutation in exon 21 being the most frequent [21, 22]. Preclinical data were generated to confirm such findings, and a number of randomised trials comparing TKIs with platinum-based chemotherapy were performed in EGFR-mutated patients, invariably showing a dramatically superior progression-free survival (PFS) in favour of TKIs (9-13 vs 5-7 months) with RR of about $60-70 \%$ [23-28]. In short, gefitinib (which has been reapproved by the FDA) and erlotinib (both firstgeneration TKIs) and, more recently, afatinib (second-generation TKI) are nowadays first-line options in several countries for patients with EGFR-mutant NSCLC, and as a result, clinical guidelines are largely concordant in recommending EGFR mutation analysis in all patients with advanced nonsquamous histology regardless of clinical characteristics. Clinicians should review EGFR testing results before commencing any systemic treatment; therefore, it is crucial to have a quick turnaround time for the analysis. But how many patients are expected to be eligible for first-line TKIs? Interestingly while sensitising, EGFR mutations are identified in about $10 \%-15 \%$ of Caucasian patients, they occur in up to $60 \%$ of Asian populations with NSCLC [29], and the reason for such a difference remains largely unknown. 
Despite the initial benefit from EGFR TKIs, patients will ultimately develop acquired resistance, which, in up to $60 \%$ of cases, is mediated by the development of a secondary mutation in exon 20 , the T790M, as shown by rebiopsies performed at the time of disease progression [30]. The T790M mutation causes treatment failure by increasing adenosine triphosphate (ATP) affinity within the ATP-binding pocket in the EGFR tyrosine kinase domain rather than sterically blocking drug binding [31]. Understanding of the T790M biology prompted the development of agents that can selectively bind to the T790M mutant allele with a minimal activity against wild-type EGFR, which is responsible for toxicity caused by first- and second-generation TKIs [32]. Recently, osimertinib, a third-generation EGFR TKI, has been approved by FDA and EMA for patients with acquired resistance to first- and second-generation TKIs mediated by the T790M mutation. In the phase II singlearm AURA-2 study, osimertinib showed antitumour efficacy in T790M-mediated acquired resistance in patients pretreated with EGFR TKIs with an RR of $62 \%$ and a PFS of 12.3 months [33]. More recently, the drug was compared with platinum-pemetrexed chemotherapy in T790M-positive patients after first-line TKI failure in the AURA-3 trial [34]. The drug showed improved PFS (10.1 vs 4.4 months, $p<0.001$ ) and $\operatorname{RR}(71 \%$ vs $31 \%, p<0.001)$, and the benefit was confirmed in patients with brain metastases. The drug has also showed promising activity against central nervous system (CNS) metastases, including leptomeningeal disease [35]. Overall, these data clearly indicate that the T790M mutation should be carefully sought in EGFR-mutant patients progressing under first-line TKIs. Today, we know that the test can be reliably performed with a simple blood test by analysing cell-free DNA and, more recently, urine samples have been deemed suitable as well, with sensitivity $>70 \%[36,37]$. Based on these data, rebiopsy could be limited only to patients with a T790M-negative blood/urine test.

Soon after osimertinib become available in several countries for T790M-mediated resistance on first- or second-generation TKI, data from the eagerly awaited phase III FLAURA trial showed that osimertinib is clearly superior, in terms of PFS, over gefitinib or erlotinib in the firstline setting in patients with common EGFR mutations (18.9 vs 10.2 months, HR 0.46; $p<0.0001$ ), with a trend for better OS [38]. These findings led to Breakthrough Therapy Designation by FDA and will likely establish first-line osimertinib as a new standard of care for EGFRmutant NSCLC, limiting the penetration in clinical practice of more recently developed strategies for TKI-naïve patients such as dacomitinib, a second-generation TKI [39], or the combination of erlotinib and bevacizumab [40].

The key issue will now be to elucidate mechanisms of acquired resistance to first-line osimertinib and understand how to best to treat patients at disease progression.

\section{Anaplastic Lymphoma Kinase (ALK) rearrangements}

ALK is the second target after EGFR to have reached clinical relevance in NSCLC, after its discovery in 2007 [41], with an increasing number of ALK inhibitors becoming available in clinical practice. ALK is a member of the insulin receptor superfamily of tyrosine kinases. Chromosomal rearrangements of $A L K$ are present in 3\%-7\% of NSCLCs and are associated with adenocarcinoma histology, lower age at diagnosis and never/light smoker status [42]. The resulting ALK fusions, such as EML4-ALK, showed responsiveness of ALK-positive tumours to ALK TKIs [43].

Crizotinib is an oral inhibitor of ALK currently approved in several countries for the treatment of ALK-positive and, more recently, ROS1positive NSCLCs. It showed a statistically and clinically significant improvement of RR and PFS compared with chemotherapy either in pretreated ALK-positive patients and, more importantly, in the first-line setting [44, 45]. Particularly, in treatment-naïve patients, responses were observed in $74 \%$ of those receiving crizotinib, with an impressive PFS of 10.9 months. Based on these findings, detection of ALK rearrangements with either fluorescence in situ hybridisation (FISH) or IHC has become part of the diagnostic workout of patients with nonsquamous histology [46]. Similarly to EGFR-mutant tumours progressing under TKIs, patients harbouring ALK rearrangements will ultimately acquire resistance to crizotinib due to a variety of mechanisms, with secondary ALK mutations representing the most investigated [47], and with CNS as one common site of metastatisation [48]. Thus, second- and third-generation ALK inhibitors have been developed to overcome acquired resistance to crizotinib, each with its own spectrum of activity against ALK mutations [49]. Ceritinib, alectinib and, more recently, brigatinib have all been approved by FDA in crizotinib-resistant patients, with no requirement for the identification of the mechanism responsible for crizotinib failure.

In the phase II ASCEND-2 trial, ceritinib was tested in crizotinib-refractory patients obtaining an encouraging RR of $38.6 \%$ and a PFS of 5.7 months and with a substantial intracranial activity [50]. The drug is active also in crizotinib-naïve patients, as shown by a recent randomised phase III clinical trial, ASCEND 4, where the comparator arm was platinum/pemetrexed chemotherapy and where PFS of patients receiving 
ceritinib reached a never-before-seen value of 16.6 months [51]. These data suggest that ceritinib could be potentially more active than crizotinib in patients with ALK-positive tumours naïve to TKIs, despite the absence of head-to-head randomised studies.

Similarly to ceritinib, alectinib showed significant activity in patients refractory to crizotinib in phase II trials (NP28673 and NP28761 studies) [52-54], but a different development strategy has been pursued in the TKI-naive setting. In fact, alectinib has been compared with crizotinib in two phase III randomised trials, J-ALEX, conducted in Japanese patients [55], and ALEX, a global study [56], with PFS as the primary endpoint. Both trials showed superior PFS for alectinib versus crizotinib with HR 0.34, p $<0.0001$ in J-ALEX and HR $0.47, p<0.001$ in ALEX. Based on these results, alectinib has been recently approved by the FDA as a first-line treatment in ALK-positive NSCLC, leading one to wonder whether there will still be room for crizotinib in the treatment algorithm of patients with ALK rearrangements.

More recently, brigatinib was granted FDA approval based on results from the phase I/II ALTA trial, where RR was 72\% (51/71) in the cohort of crizotinib-resistant patients, with a favourable toxicity profile and with the evidence of promising intracranial activity [57].

Several other ALK TKIs are under development, including lorlatinib, ensartinib and entrectinib, to mention a few. Only time and, most of all, clinical trials will tell us which agent(s) will make it to the clinical arena and how to incorporate each molecule in the treatment strategy of ALK-positive NSCLC. Indeed, there is an evidence that the sequential use of different ALK TKIs could be beneficial to some patients [58], but a better knowledge of resistance mechanisms will likely be crucial to establish which agent to use and when.

\section{Beyond EGFR and ALK: novel actionable targets}

Besides EGFR gene mutations and $A L K$ gene rearrangements, which should be tested upfront in all patients with advanced nonsquamous NSCLC, other actionable targets have been recently identified and new genomic-driven agents are expanding the therapeutic arsenal against NSCLC. We will briefly review the targets with higher therapeutic interest and/or with potential clinical implementation in the next few years.

ROS1 is a receptor tyrosine kinase that has high homology to ALK [59]. ROS1 gene fusions are found in approximately $2 \%$ of NSCLCs, seem to be mutually exclusive with other oncogenic driver genes and have been associated with nonsmoking history [60]. The high homology between ROS1 and ALK renders ROS1-rearranged tumours sensitive to several ALK inhibitors. Crizotinib demonstrated a potent inhibitory activity against ROS1 in a single-arm study with a median PFS of 19.2 months and an RR of 72\% [61], leading to FDA and EMA approval for patients with ROS1-rearranged NSCLC.

BRAF is a well-established target in melanoma, where the commonly observed V600E point mutation leads to constitutive BRAF signalling and sensitivity to BRAF inhibitors [62]. More recently promising results have been observed in BRAF-mutant NSCLC. BRAF mutations occur in $1.6 \%-3 \%$ of NSCLCs and V600E represents about half of cases [63]. The V600E mutation has been associated with a more aggressive behavior, with poorer prognosis and is more common in females and less associated with smoking history [63, 64]. Dabrafenib and vemurafenib demonstrated promising single-agent efficacy in advanced NSCLC with V600E BRAF mutation, with an RR of $40 \%-42 \%$ in phase II trials $[65,66]$. However, as in melanoma, drug combinations appear to yield increased efficacy in V600E BRAF-mutant NSCLC, with dabrafenib plus trametinib, an MEK inhibitor, showing an impressive RR of $63 \%$ and a PFS of 9.7 months [67]. This combination regimen was recently granted FDA Breakthrough Therapy Designation and received a recommendation for approval by the EMA Committee for Medicinal Products for Human Use (CHMP).

RET gene rearrangements have been firstly identified in papillary thyroid cancer and, more recently in about $1 \%-2 \%$ of unselected NSCLC [68]. In the phase II LURET trial, 17 RET-rearranged NSCLC were treated with vandetanib, a multitargeted TKI, with $53 \%$ RR and a relatively short, if compared with other genomic-driven treatment in NSCLC, median PFS of 4.7 [69]. No better results were obtained with cabozantinib in the same setting, with a $28 \%$ RR in 25 patients [70]. The hard time clinicians are experiencing in treating RET-positive NSCLC was recently confirmed by a retrospective analysis of 53 patients with RET-rearranged NSCLC treated with different RET-inhibitors, with RR up to $37 \%$ and median PFS of only 2.3 months [71]. These findings highlight the need for a better understanding of the biology of RETrearranged lung cancers to improve outcomes for these patients. 
The MET/hepatocyte growth factor (HGF) pathway has been identified as a potential therapeutic target in multiple solid tumours, including NSCLC [72]. Aberrant MET activation can be caused by several altered biological processes, but mainly two are of clinical interest in NSCLC: MET gene amplification, which is observed in $2 \%-4 \%$ of NSCLC, and MET exon 14 skip mutations, which have been found in $3 \%-4 \%$ of lung adenocarcinomas [73, 74]. Several agents with antiMET activity, including crizotinib, cabozantinib and capmatinib, have shown some degree of efficacy in patients with MET-amplified or mutant (exon 14 skipping) NSCLC, and some new agents are under investigation in this setting [75].

\section{Checkpoint inhibitors: the unexpected comeback of immunotherapy}

In the era of precision medicine, where genomically driven-treatments are paving the way for the present and future of NSCLC, immunotherapy has made an unexpected, for many, comeback after a number of clinical failures. In fact, some degree of disbelief in the role of immunotherapy in NSCLC has arisen after large phase III trials failed to demonstrate a survival advantage for lung cancer vaccines over placebo in the adjuvant setting or as maintenance strategy in patients undergoing chemoradiation for locally advanced disease [76, 77]. Nevertheless, research efforts have been rewarded and between 2015 and 2016, four randomised phase III trials showed a clinically meaningful survival advantage for antiPD1 and PD-L1 agents (nivolumab, pembrolizumab and atezolizumab) over docetaxel in the second- and third-line setting [78-81], leading to the registration of these checkpoint inhibitors by the FDA and other regulatory agencies. This was just the beginning, or rather the close postbeginning - given the earlier success in melanoma - of the immunotherapy revolution, with several pharmaceutical companies now developing their own checkpoint inhibitor(s), not only in NSCLC.

Why are checkpoint inhibitors becoming so successful in cancer, with now several FDA-approved indications in solid tumours over the past few years? In the early phases of cancer development, a competent immune system destroys transformed cells, but through a variety of mechanisms, including expression of immunosuppressive factors like PD-L1, cancer cells can escape immune system surveillance [82]. In fact, PD-L1, expressed on the surface of tumour and infiltrating immune cells with immunosuppressive activity, interacts with PD-1, which is present on activated T-cells, causing immune escape. PD-1 and PD-L1 checkpoint inhibitors are monoclonal antibodies that disrupt PD-1/PD-L1-mediated signalling restoring antitumour immunity. Looking at the often impressive results from clinical trials with checkpoint inhibitors, this mechanism of immune escape occurs across several human malignancies, although patient selection remains a largely unresolved issue.

The first phase III positive trial in advanced NSCLC was CheckMate-017, where nivolumab, a fully human IgG4 antiPD1 monoclonal antibody, was compared with docetaxel as the second-line treatment in patients with squamous cell histology [78]. Median OS was significantly improved for nivolumab (9.2 vs 6.0 months; HR 0.59, $p<0.001)$, as well as RR $(20 \%$ vs $9 \%, p=0.008)$ and median PFS $(3.5$ vs 2.8 months; HR 0.62, $p<0.001)$. These results were partly replicated in the CheckMate- 057 trial, performed in patients with nonsquamous histology, where nivolumab yielded superior median OS over docetaxel (12.2 vs 9.4 months; HR 0.73, $p=0.0015)$ [79]. The two CheckMate studies were closely followed by two other positive phase III trials, again versus docetaxel, with pembrolizumab [80], a humanised antiPD1 IgG4 monoclonal antibody, which has been developed as single agent exclusively in PD-L1-expressing tumours, and atezolizumab [81], a humanised IgG1antibody against PD-L1. Overall, these agents have an extremely favourable toxicity profile, with grade 3-4 adverse events occurring in no more than $15 \%$ of patients (vs $40 \%-50 \%$ with docetaxel) and with immune-related toxicity being generally manageable with steroids.

While in several countries PD-1/PD-L1 checkpoint inhibitors are/were yet to become available for pretreated patients, a groundbreaking trial opened the path for immunotherapy in first line. In fact, in the phase III KEYNOTE-024 trial, untreated subjects with advanced NSCLC whose tumours expressed high levels of PD-L1 (tumour proportion score, TPS, $\geq 50 \%$ ), which represent about $1 / 3$ of the screened population, were randomised to pembrolizumab or platinum-based chemotherapy [83]. The study showed a clear superiority of pembrolizumab in terms of PFS (median 10.3 vs 6.0 months; HR 0.50, p < 0.001), which was the primary endpoint, and OS (HR 0.60; $p=0.005$ ), leading most guidelines to recommend PD-L1 testing in the diagnostic workout of patients with advanced NSCLC.

While the first-line algorithm looks relatively linear, the use of PD-1/PD-L1 inhibitors in the second (or third) line is generating much discussion. In fact, despite being welcomed with great enthusiasm by several clinicians, patients and media, checkpoint inhibitors cannot 
be considered the best option for every subject with advanced pretreated NSCLC. A major matter of debate is whether testing for PD-L1 expression, with the exception of pembrolizumab prescription, which requires a PD-L1-positive test (TPS $\geq 1 \%$ ), could be a useful tool for patient selection, at least for nonsquamous histology (in the CheckMate-017 in squamous histology, PD-L1 was not predictive for nivolumab benefit). In fact, while several data suggest that RR, PFS and OS increase with PD-L1 levels [79-81, 84], there are patients with PD-L1 negative tumours who can still achieve a durable benefit from PD-1/PD-L1 inhibitors [79], indicating that a PD-L1-negative test should not necessarily exclude a patient from treatment. A still open question is how to reliably test for PD-L1 expression and if results from clinical trials are reproducible, given the different assays and cut-offs explored in each drug development, although harmonisation studies have been carried on and results are out there to let clinicians and pathologists make their choice [85, 86]. Emerging data suggest that novel potential markers could add to the complex picture of patient selection, including tumour mutation burden [87], but none of these looks broadly applicable in clinical practice in the short term. Indeed, some clinical and biological characteristics could aid the clinician in treatment decision making. For example, never-smoking history or presence of EGFR mutations or ALK rearrangements are among the subgroups less likely to benefit from anti-PD-1/PD-L1 agents [79-81], likely as a result of lower mutational burden [88], although the small number of patients with these characteristics included in clinical trials and the inevitably large confidence intervals should call for some caution and further investigation. At the same time, we should acknowledge that a substantial fraction of patients progressing under first-line platinum-based chemotherapy is unfit for triweekly docetaxel. This observation, together with the absence of subgroups where immunotherapy is overtly detrimental, may lead clinicians to opt for checkpoint inhibitors for all patients unfit for docetaxel, with potential overuse - also considering that the optimal treatment duration has not been defined yet - of these agents and with the risk of a significant economic impact on national health systems.

\section{Conclusion}

Treatment of NSCLC is witnessing years of exciting progress with tangible improvements of patient outcome. The success of genomically driven treatments for small subgroups of patients highlights the need to test for selected molecular alterations in the clinical setting and calls for the identification of novel actionable targets. In parallel, clinical research should move forward from the traditional phase I-III drug development model, at least in the setting of oncogene-addicted tumours, promoting biomarker-driven studies, such as basket and umbrella trials, to grant timely access to new active agents to patients.

Additionally, as more and more agents become available, it will be increasingly crucial to understand how to best sequence treatments. To achieve this goal, clinicians and researchers should strive to systematically characterise mechanisms of resistance, with liquid biopsy potentially representing an ideal ally, given the noninvasiveness of sample collection and the ability of next-generation sequencing approaches to detect actionable targets on circulating tumour DNA [89].

In contrast, in the era of precision medicine, we are experiencing the paradox of immunotherapy, with the lack of reliable predictors of benefit and, more importantly, resistance, therefore drifting away from treatment personalisation. Indeed, these agents can produce durable benefit in NSCLC patients with diverse clinical characteristics and with long-term survival rates exceeding those of historical controls [90], but patient selection requires further refinement. The favourable safety profile of checkpoint inhibitors led to several ongoing clinical trials currently exploring combination strategies (i.e. checkpoint inhibitors with chemotherapy or targeted agents or multiple immune-oncology agents together) in order to tackle either intrinsic or acquired resistance, sometimes with limited preclinical evidence of synergistic effects. In this rush to develop novel treatment strategies, the substantial risk of added toxicity and the almost certain financial burden should be taken into account.

Finally, there is an urgent need to translate the improvements observed in advanced disease into the curative setting, where little progress, if any, has occurred in the past decade. The recent striking PFS benefit showed by the anti-PD-L1 agent durvalumab when compared with placebo as maintenance treatment after chemoradiation for stage III disease [91] is noteworthy and hopefully will increase cure rates in a setting where targeted agents have failed so far. Similarly, much hope is placed in the ongoing clinical trials with checkpoint inhibitors in the adjuvant setting, where the success rate of conventional treatments remains largely suboptimal. 


\section{References}

1. Schiller JH, Harrington D, and Belani CP, et al (2002) Comparison of four chemotherapy regimens for advanced non-small-cell lung cancer N Engl J Med 346 92-98 https://doi.org/10.1056/NEJMoa011954 PMID: 11784875

2. Johnson DH, Fehrenbacher L, and Novotny WF, et al (2004) Randomized phase II trial comparing bevacizumab plus carboplatin and paclitaxel with carboplatin and paclitaxel alone in previously untreated locally advanced or metastatic non-small-cell lung cancer J Clin Oncol 22 2184-2191 https://doi.org/10.1200/JCO.2004.11.022 PMID: 15169807

3. Sandler A, Gray R, and Perry MC, et al (2006) Paclitaxel-carboplatin alone or with bevacizumab for non-small-cell lung cancer N Engl J Med 355 2542-2550 https://doi.org/10.1056/NEJMoa061884 PMID: 17167137

4. Reck M, von Pawel J, and Zatloukal P, et al (2010) Overall survival with cisplatin-gemcitabine and bevacizumab or placebo as first-line therapy for nonsquamous non-small-cell lung cancer: results from a randomised phase III trial (AVAiL) Ann Oncol 21 1804-1809 https://doi.org/10.1093/annonc/mdq020 PMID: 20150572 PMCID: 2924992

5. Garon EB, Ciuleanu T-E, and Arrieta O, et al (2014) Ramucirumab plus docetaxel versus placebo plus docetaxel for second-line treatment of stage IV non-small-cell lung cancer after disease progression on platinum-based therapy (REVEL): a multicentre, double-blind, randomised phase 3 trial Lancet 384 665-673 https://doi.org/10.1016/S0140-6736(14)60845-X PMID: 24933332

6. Reck M, Kaiser R, and Mellemgaard A, et al (2014) Docetaxel plus nintedanib versus docetaxel plus placebo in patients with previously treated non-small-cell lung cancer (LUME-Lung 1): a phase 3, double-blind, randomised controlled trial Lancet Oncol 15 143-155 https://doi.org/10.1016/S1470-2045(13)70586-2 PMID: 24411639

7. Scagliotti GV, Parikh P, and von Pawel J, et al (2008) Phase III study comparing cisplatin plus gemcitabine with cisplatin plus pemetrexed in chemotherapy-naive patients with advanced-stage non-small-cell lung cancer J Clin Oncol 26 $3543-3551$ https://doi.org/10.1200/JCO.2007.15.0375 PMID: 18506025

8. Scagliotti G, Hanna N, and Fossella F, et al (2009) The differential efficacy of pemetrexed according to NSCLC histology: a review of two phase III studies Oncologist 14 253-263 https://doi.org/10.1634/theoncologist.2008-0232 PMID: 19221167

9. Paz-Ares LG, de Marinis F, and Dediu M, et al (2013) PARAMOUNT: final overall survival results of the phase III study of maintenance pemetrexed versus placebo immediately after induction treatment with pemetrexed plus cisplatin for advanced nonsquamous non-small-cell lung cancer J Clin Oncol 31 2895-2902 https://doi.org/10.1200/JC0.2012.47.1102 PMID: 23835707

10. Paz-Ares L, Mezger J, and Ciuleanu TE, et al (2015) Necitumumab plus pemetrexed and cisplatin as first-line therapy in patients with stage IV non-squamous non-small-cell lung cancer (INSPIRE): an open-label, randomised, controlled phase 3 study Lancet Oncol 16 328-337 https://doi.org/10.1016/S1470-2045(15)70046-X PMID: 25701171

11. Thatcher N, Hirsch FR, and Luft AV, et al (2015) Necitumumab plus gemcitabine and cisplatin versus gemcitabine and cisplatin alone as first-line therapy in patients with stage IV squamous non-small-cell lung cancer (SQUIRE): an open-label, randomised, controlled phase 3 trial Lancet Oncol 16 763-774 https://doi.org/10.1016/S1470-2045(15)00021-2 PMID: 26045340

12. Paz-Ares L, Socinski MA, and Shahidi J, et al (2016) Correlation of EGFR-expression with safety and efficacy outcomes in SQUIRE: a randomized, multicenter, open-label, phase III study of gemcitabine-cisplatin plus necitumumab versus gemcitabine-cisplatin alone in the first-line treatment of patients with stage IV squamous non-small-cell lung cancer Ann Oncol 27 1573-1579 https://doi.org/10.1093/annonc/mdw214 PMID: 27207107 PMCID: 4959928

13. Rusch V, Baselga J, and Cordon-Cardo C, et al (1993) Differential expression of the epidermal growth factor receptor and its ligands in primary non-small cell lung cancers and adjacent benign lung Cancer Res 53 2379-2385 PMID: 7683573

14. Giaccone G, Herbst RS, and Manegold C, et al (2004) Gefitinib in combination with gemcitabine and cisplatin in advanced non-small-cell lung cancer: a phase III trial-INTACT 1 J Clin Oncol 22 777-784 https://doi.org/10.1200/JCO.2004.08.001 PMID: 14990632 
15. Herbst RS, Giaccone G, and Schiller JH, et al (2004) Gefitinib in combination with paclitaxel and carboplatin in advanced non-small-cell lung cancer: a phase III trial--INTACT 2 J Clin Oncol 22 785-794 https://doi.org/10.1200/JC0.2004.07.215 PMID: 14990633

16. Herbst RS, Prager D, and Hermann R, et al (2005) TRIBUTE: a phase III trial of erlotinib hydrochloride (osi-774) combined with carboplatin and paclitaxel chemotherapy in advanced non-small-cell lung cancer J Clin Oncol 23 5892-5899 https://doi. org/10.1200/JCO.2005.02.840 PMID: 16043829

17. Gatzemeier U, Pluzanska A, and Szczesna A, et al (2007) Phase III study of erlotinib in combination with cisplatin and gemcitabine in advanced non-small-cell lung cancer: the tarceva lung cancer investigation trial J Clin Oncol 25 1545-1552 https:// doi.org/10.1200/JCO.2005.05.1474 PMID: 17442998

18. Kris MG, Natale RB, and Herbst RS, et al (2003) Efficacy of gefitinib, an inhibitor of the epidermal growth factor receptor tyrosine kinase, in symptomatic patients with non-small cell lung cancer JAMA 2902149 https://doi.org/10.1001/jama.290.16.2149 PMID: 14570950

19. Fukuoka M, Yano S, and Giaccone G, et al (2003) Multi-institutional randomized phase II trial of gefitinib for previously treated patients with advanced non-small-cell lung cancer J Clin Oncol 21 2237-2246 https://doi.org/10.1200/JC0.2003.10.038 PMID: 12748244

20. Thatcher N, Chang A, and Parikh P, et al (2005) Gefitinib plus best supportive care in previously treated patients with refractory advanced non-small-cell lung cancer: results from a randomised, placebo-controlled, multicentre study (iressa survival evaluation in lung cancer) Lancet 366 1527-1537 https://doi.org/10.1016/S0140-6736(05)67625-8 PMID: 16257339

21. Lynch TJ, Bell DW, and Sordella R, et al (2004) Activating mutations in the epidermal growth factor receptor underlying responsiveness of non-small-cell lung cancer to gefitinib N Engl J Med 350 2129-2139 https://doi.org/10.1056/NEJMoa040938 PMID: 15118073

22. Paez JG, Jänne PA, and Lee JC, et al (2004) EGFR mutations in lung cancer: correlation with clinical response to gefitinib therapy Science 304: 1497-1500 https://doi.org/10.1126/science.1099314 PMID: 15118125

23. Mitsudomi T, Morita S, and Yatabe Y, et al (2010) Gefitinib versus cisplatin plus docetaxel in patients with non-small-cell lung cancer harbouring mutations of the epidermal growth factor receptor (WJTOG3405): an open label, randomised phase 3 trial Lancet Oncol 11 121-128 https://doi.org/10.1016/S1470-2045(09)70364-X

24. Maemondo M, Inoue A, and Kobayashi K, et al (2010) Gefitinib or chemotherapy for non-small-cell lung cancer with mutated EGFR N Engl J Med 362 2380-2388 https://doi.org/10.1056/NEJMoa0909530 PMID: 20573926

25. Zhou C, Wu Y-L, and Chen G, et al (2011) Erlotinib versus chemotherapy as first-line treatment for patients with advanced EGFR mutation-positive non-small-cell lung cancer (OPTIMAL, CTONG-0802): a multicentre, open-label, randomised, phase 3 study Lancet Oncol 12 735-742 https://doi.org/10.1016/S1470-2045(11)70184-X PMID: 21783417

26. Rosell R, Carcereny E, and Gervais R, et al (2012) Erlotinib versus standard chemotherapy as first-line treatment for European patients with advanced EGFR mutation-positive non-small-cell lung cancer (EURTAC): a multicentre, open-label, randomised phase 3 trial Lancet Oncol 13 239-246 https://doi.org/10.1016/S1470-2045(11)70393-X PMID: 22285168

27. Wu Y-L, Zhou C, and Hu C-P, et al (2014) Afatinib versus cisplatin plus gemcitabine for first-line treatment of asian patients with advanced non-small-cell lung cancer harbouring EGFR mutations (LUX-Lung 6): an open-label, randomised phase 3 trial Lancet Oncol 15 213-222 https://doi.org/10.1016/S1470-2045(13)70604-1 PMID: 24439929

28. Sequist L V, Yang JC-H, and Yamamoto N, et al (2013) Phase III study of afatinib or cisplatin plus pemetrexed in patients with metastatic lung adenocarcinoma with EGFR mutations J Clin Oncol 31 3327-3334 https://doi.org/10.1200/JC0.2012.44.2806 PMID: $\underline{23816960}$ 
29. Kohno T, Nakaoku T, and Tsuta K, et al (2015) Beyond ALK-RET, ROS1 and other oncogene fusions in lung cancer Transl lung cancer Res 4 156-164 PMID: 25870798 PMCID: 4384213

30. Yu HA, Arcila ME, and Rekhtman N, et al (2013) Analysis of tumor specimens at the time of acquired resistance to EGFR-TKI therapy in 155 patients with EGFR-mutant lung cancers Clin Cancer Res 19 2240-2247 https://doi.org/10.1158/1078-0432.CCR12-2246 PMID: 23470965 PMCID: $\underline{3630270}$

31. Yun C-H, Mengwasser KE, and Toms AV, et al (2008) The T790M mutation in EGFR kinase causes drug resistance by increasing the affinity for ATP Proc Natl Acad Sci 105 2070-2075 https://doi.org/10.1073/pnas.0709662105 PMID: 18227510 PMCID: 2538882

32. Zhou W, Ercan D, and Chen L, et al (2009) Novel mutant-selective EGFR kinase inhibitors against EGFR T790M Nature 462 1070-1074 https://doi.org/10.1038/nature08622 PMID: 20033049 PMCID: 2879581

33. Yang JC-H, Ahn M-J, and Kim D-W, et al (2017) Osimertinib in pretreated T790M-positive advanced non-small-cell lung cancer: aura study phase II extension component J Clin Oncol 35 1288-1296 https://doi.org/10.1200/JC0.2016.70.3223 PMID: 28221867

34. Mok TS, Wu Y-L, and Ahn M-J, et al (2017) Osimertinib or platinum-pemetrexed in EGFR T790M-positive lung cancer $N$ Engl $J$ Med 376 629-640 https://doi.org/10.1056/NEJMoa1612674

35. Yang JC-H, Cho BC, and Kim D-W, et al (2017) Osimertinib for patients (pts) with leptomeningeal metastases (LM) from EGFRmutant non-small cell lung cancer (NSCLC): Updated results from the BLOOM study J Clin Oncol 352020

36. Reckamp KL, Melnikova VO, and Karlovich C, et al (2016) A highly sensitive and quantitative test platform for detection of NSCLC EGFR mutations in urine and plasma J Thorac Oncol 11 1690-1700 https://doi.org/10.1016/j.jtho.2016.05.035 PMID: 27468937

37. Oxnard GR, Thress KS, and Alden RS, et al (2016) Association between plasma genotyping and outcomes of treatment with osimertinib (AZD9291) in advanced non-small-cell lung cancer J Clin Oncol 34 3375-3382 https://doi.org/10.1200/ JCO.2016.66.7162 PMID: 27354477 PMCID: $\underline{5035123}$

38. Ramalingam SS (2017) Osimertinib vs standard of care (SoC) EGFR-TKI as first-line therapy in patients (pts) with EGFRm advanced NSCLC: FLAURA. Ann Oncol 28(5) v605-v649 https://doi.org/10.1093/annonc/mdx440.050

39. Wu Y-L, Cheng Y, and Zhou X, et al (2017) Dacomitinib versus gefitinib as first-line treatment for patients with EGFR-mutationpositive non-small-cell lung cancer (ARCHER 1050): a randomised, open-label, phase 3 trial Lancet Oncol 18(11) 1454-1466 https://doi.org/10.1016/S1470-2045(17)30608-3

40. Seto $T$, Kato $T$, and Nishio M, et al (2014) Erlotinib alone or with bevacizumab as first-line therapy in patients with advanced non-squamous non-small-cell lung cancer harbouring EGFR mutations (JO25567): an open-label, randomised, multicentre, phase 2 study Lancet Oncol 15 1236-1244 https://doi.org/10.1016/S1470-2045(14)70381-X PMID: 25175099

41. Soda M, Choi YL, and Enomoto M, et al (2007) Identification of the transforming EML4-ALK fusion gene in non-small-cell lung cancer Nature 448 561-566 https://doi.org/10.1038/nature05945 PMID: 17625570

42. Shaw AT, Yeap BY, and Mino-Kenudson M, et al (2009) Clinical features and outcome of patients with non-small-cell lung cancer who harbor EML4-ALK J Clin Oncol 27 4247-4253 https://doi.org/10.1200/JC0.2009.22.6993 PMID: 19667264 PMCID: 2744268

43. Kwak EL, Bang Y-J, and Camidge DR, et al (2010) Anaplastic lymphoma kinase inhibition in non-small-cell lung cancer $N$ Engl J Med 363 1693-1703 https://doi.org/10.1056/NEJMoa1006448 PMID: 20979469 PMCID: 3014291

44. Shaw AT, Kim D-W, and Nakagawa K, et al (2013) Crizotinib versus chemotherapy in advanced ALK-positive lung cancer $N$ Engl J Med 368 2385-2394 https://doi.org/10.1056/NEJMoa1214886 PMID: 23724913

45. Solomon BJ, Mok T, and Kim D-W, et al (2014) First-line crizotinib versus chemotherapy in ALK-positive lung cancer $N$ Engl $J$ Med 371 2167-2177 https://doi.org/10.1056/NEJMoa1408440 PMID: 25470694 
46. Yi ES, Boland JM, and Maleszewski JJ, et al (2011) Correlation of IHC and FISH for ALK gene rearrangement in non-small cell lung carcinoma: IHC score algorithm for FISH J Thorac Oncol 6 459-465 https://doi.org/10.1097/JTO.0b013e318209edb9 PMID: $\underline{21278610}$

47. Choi YL, Soda M, and Yamashita Y, et al (2010) EML4-ALK mutations in lung cancer that confer resistance to ALK inhibitors $N$ Engl J Med 363 1734-1739 https://doi.org/10.1056/NEJMoa1007478 PMID: 20979473

48. Costa DB, Shaw AT, and Ou S-HI, et al (2015) Clinical experience with crizotinib in patients with advanced ALK-rearranged non-small-cell lung cancer and brain metastases J Clin Oncol 33 1881-1888 https://doi.org/10.1200/JC0.2014.59.0539 PMID: 25624436 PMCID: 4451171

49. Gainor JF, Dardaei L, and Yoda S, et al (2016) Molecular mechanisms of resistance to first- and second-generation ALK inhibitors in ALK-rearranged lung cancer Cancer Discov 6 1118-1133 https://doi.org/10.1158/2159-8290.CD-16-0596 PMID: 27432227 PMCID: $\underline{5050111}$

50. Crinò L, Ahn M-J, and De Marinis F, et al (2016) Multicenter phase Il study of whole-body and intracranial activity with ceritinib in patients with ALK-rearranged non-small-cell lung cancer previously treated with chemotherapy and crizotinib: results from ASCEND-2 J Clin Oncol 34 2866-2873 https://doi.org/10.1200/JC0.2015.65.5936

51. Soria J-C, Tan DSW, and Chiari R, et al (2017) First-line ceritinib versus platinum-based chemotherapy in advanced ALKrearranged non-small-cell lung cancer (ASCEND-4): a randomised, open-label, phase 3 study Lancet 389 917-929 https://doi. org/10.1016/S0140-6736(17)30123-X PMID: $\underline{28126333}$

52. Shaw AT, Gandhi L, and Gadgeel S, et al (2016) Alectinib in ALK-positive, crizotinib-resistant, non-small-cell lung cancer: a single-group, multicentre, phase 2 trial Lancet Oncol 17 234-242 https://doi.org/10.1016/S1470-2045(15)00488-X

53. Barlesi F, Dingemans A-MC, and Yang J-H, et al (2016) Updated efficacy and safety from the global phase II NP28673 study of alectinib in patients (pts) with previously treated ALK+ non-small-cell lung cancer (NSCLC) Ann Oncol 27(6) 416-454 https:// doi.org/10.1093/annonc/mdw383.63

54. Gadgeel SM, Gandhi L, and Riely GJ, et al (2014) Safety and activity of alectinib against systemic disease and brain metastases in patients with crizotinib-resistant ALK-rearranged non-small-cell lung cancer (AF-002JG): results from the dose-finding portion of a phase 1/2 study Lancet Oncol 15 1119-1128 https://doi.org/10.1016/S1470-2045(14)70362-6 PMID: 25153538

55. Hida T, Nokihara H, and Kondo M, et al (2017) Alectinib versus crizotinib in patients with ALK-positive non-small-cell lung cancer (J-ALEX): an open-label, randomised phase 3 trial Lancet 390 29-39 https://doi.org/10.1016/S0140-6736(17)30565-2 PMID: $\underline{28501140}$

56. Peters S, Camidge DR, and Shaw AT, et al (2017) Alectinib versus crizotinib in untreated ALK-positive non-small-cell lung cancer N Engl J Med 377 829-838 https://doi.org/10.1056/NEJMoa1704795 PMID: 28586279

57. Gettinger SN, Bazhenova LA, and Langer CJ, et al (2016) Activity and safety of brigatinib in ALK-rearranged non-small-cell lung cancer and other malignancies: a single-arm, open-label, phase 1/2 trial Lancet Oncol 17 1683-1696 https://doi.org/10.1016/ S1470-2045(16)30392-8 PMID: 27836716

58. Shaw AT, Friboulet L, and Leshchiner I, et al (2016) Resensitization to crizotinib by the lorlatinib ALK resistance mutation L1198F N Engl J Med 374 54-61 https://doi.org/10.1056/NEJMoa1508887

59. Chin LP, Soo RA, and Soong R, et al (2012) Targeting ROS1 with anaplastic lymphoma kinase inhibitors: a promising therapeutic strategy for a newly defined molecular subset of non-small-cell lung cancer J Thorac Oncol 7 1625-1630 https://doi. org/10.1097/JTO.0b013e31826baf83 PMID: 23070242

60. Bergethon K, Shaw AT, and Ou S-H, et al (2012) ROS1 rearrangements define a unique molecular class of lung cancers $J$ Clin Oncol 30 863-870 https://doi.org/10.1200/JCO.2011.35.6345 PMID: 22215748 PMCID: 3295572 
61. Shaw AT, Ou S-HI, and Bang Y-J, et al (2014) Crizotinib in ROS1-rearranged non-small-cell lung cancer N Engl J Med 371 1963-1971 https://doi.org/10.1056/NEJMoa1406766 PMID: 25264305 PMCID: 4264527

62. Tsai J, Lee JT, and Wang W, et al (2008) Discovery of a selective inhibitor of oncogenic B-Raf kinase with potent antimelanoma activity Proc Natl Acad Sci 105 3041-3046 https://doi.org/10.1073/pnas.0711741105 PMID: 18287029 PMCID: 2268581

63. Paik PK, Arcila ME, and Fara M, et al (2011) Clinical characteristics of patients with lung adenocarcinomas harboring BRAF mutations J Clin Oncol 29 2046-2051 https://doi.org/10.1200/JCO.2010.33.1280 PMID: 21483012 PMCID: 3107760

64. Cardarella S, Ogino A, and Nishino M, et al (2013) Clinical, pathologic, and biologic features associated with BRAF mutations in non-small cell lung cancer Clin Cancer Res 19 4532-4540 https://doi.org/10.1158/1078-0432.CCR-13-0657 PMID: 23833300 PMCID: $\underline{3762878}$

65. Planchard D, Kim TM, and Mazieres J, et al (2016) Dabrafenib in patients with BRAFV600E-positive advanced non-smallcell lung cancer: a single-arm, multicentre, open-label, phase 2 trial Lancet Oncol 17 642-650 https://doi.org/10.1016/S14702045(16)00077-2 PMID: 27080216 PMCID: $\underline{5006181}$

66. Hyman DM, Puzanov I, and Subbiah V, et al (2015) Vemurafenib in multiple nonmelanoma cancers with BRAF V600 mutations N Engl J Med 373 726-736 https://doi.org/10.1056/NEJMoa1502309 PMID: 26287849 PMCID: 4971773

67. Planchard D, Besse B, and Groen HJM, et al (2016) Dabrafenib plus trametinib in patients with previously treated BRAFV600Emutant metastatic non-small cell lung cancer: an open-label, multicentre phase 2 trial Lancet Oncol 17 984-993 https://doi. org/10.1016/S1470-2045(16)30146-2 PMID: 27283860 PMCID: 4993103

68. Wang R, Hu H, and Pan Y, et al (2012) RET fusions define a unique molecular and clinicopathologic subtype of non-small-cell lung cancer J Clin Oncol 30 4352-4359 https://doi.org/10.1200/JCO.2012.44.1477 PMID: 23150706

69. Yoh K, Seto T, and Satouchi M, et al (2017) Vandetanib in patients with previously treated RET-rearranged advanced non-smallcell lung cancer (LURET): an open-label, multicentre phase 2 trial Lancet Respir Med 5 42-50 https://doi.org/10.1016/S2213$\underline{2600(16) 30322-8}$

70. Drilon A, Rekhtman N, and Arcila M, et al (2016) Cabozantinib in patients with advanced RET-rearranged non-small-cell lung cancer: an open-label, single-centre, phase 2, single-arm trial Lancet Oncol 17 1653-1660 https://doi.org/10.1016/S14702045(16)30562-9 PMID: 27825636 PMCID: $\underline{5143197}$

71. Gautschi O, Milia J, and Filleron T, et al (2017) Targeting RET in patients with RET-rearranged lung cancers: results from the global, multicenter RET registry J Clin Onco/ 35 1403-1410 https://doi.org/10.1200/JCO.2016.70.9352 PMID: 28447912 PMCID: $\underline{559893}$

72. Finocchiaro G, Toschi L, and Gianoncelli L, et al (2015) Prognostic and predictive value of MET deregulation in non-small cell lung cancer Ann Transl Med 383 PMID: 25992382 PMCID: 4416957

73. Onozato R, Kosaka $\mathrm{T}$, and Kuwano $\mathrm{H}$, et al (2009) Activation of MET by gene amplification or by splice mutations deleting the juxtamembrane domain in primary resected lung cancers $J$ Thorac Oncol 4 5-11 https://doi.org/10.1097/JTO.0b013e3181913e0e

74. Awad MM, Oxnard GR, and Jackman DM, et al (2016) MET exon 14 mutations in non-small-cell lung cancer are associated with advanced age and stage-dependent MET genomic amplification and c-Met overexpression J Clin Oncol 34 721-730 https://doi. org/10.1200/JCO.2015.63.4600 PMID: 26729443

75. Reungwetwattana $T$, Liang $Y$, and Zhu $V$, et al (2017) The race to target MET exon 14 skipping alterations in non-small cell lung cancer: the why, the how, the who, the unknown, and the inevitable Lung Cancer 103 27-37 https://doi.org/10.1016/j.lungcan.2016.11.011 
76. Vansteenkiste JF, Cho BC, and Vanakesa T, et al (2016) Efficacy of the MAGE-A3 cancer immunotherapeutic as adjuvant therapy in patients with resected MAGE-A3-positive non-small-cell lung cancer (MAGRIT): a randomised, double-blind, placebocontrolled, phase 3 trial Lancet Oncol 17 822-835 https://doi.org/10.1016/S1470-2045(16)00099-1 PMID: 27132212

77. Butts C, Socinski MA, and Mitchell PL, et al (2014) Tecemotide (L-BLP25) versus placebo after chemoradiotherapy for stage III non-small-cell lung cancer (START): a randomised, double-blind, phase 3 trial Lancet Oncol 15 59-68 https://doi.org/10.1016/ S1470-2045(13)70510-2

78. Brahmer J, Reckamp KL, and Baas P, et al (2015) Nivolumab versus docetaxel in advanced squamous-cell non-small-cell lung cancer N Engl J Med 373 123-135 https://doi.org/10.1056/NEJMoa1504627 PMID: 26028407 PMCID: 4681400

79. Borghaei $\mathrm{H}$, Paz-Ares $\mathrm{L}$, and Horn $\mathrm{L}$, et al (2015) Nivolumab versus docetaxel in advanced nonsquamous non-small-cell lung cancer N Engl J Med 373 1627-1639 https://doi.org/10.1056/NEJMoa1507643 PMID: 26412456

80. Herbst RS, Baas P, and Kim D-W, et al (2016) Pembrolizumab versus docetaxel for previously treated, PD-L1-positive, advanced non-small-cell lung cancer (KEYNOTE-010): a randomised controlled trial Lancet 387 1540-1550 https://doi.org/10.1016/S01406736(15)01281-7

81. Rittmeyer A, Barlesi F, and Waterkamp D, et al (2017) Atezolizumab versus docetaxel in patients with previously treated nonsmall-cell lung cancer (OAK): a phase 3, open-label, multicentre randomised controlled trial Lancet 389 255-265 https://doi. org/10.1016/S0140-6736(16)32517-X

82. Sznol M and Chen L (2013) Antagonist antibodies to PD-1 and B7-H1 (PD-L1) in the treatment of advanced human cancer Clin Cancer Res 19 1021-1034 https://doi.org/10.1158/1078-0432.CCR-12-2063 PMID: 23460533 PMCID: 3702373

83. Reck M, Rodríguez-Abreu D, and Robinson AG, et al (2016) Pembrolizumab versus chemotherapy for PD-L1-positive nonsmall-cell lung cancer N Engl J Med 375 1823-1833 https://doi.org/10.1056/NEJMoa1606774 PMID: 27718847

84. Garon EB, Rizvi NA, and Hui R, et al (2015) Pembrolizumab for the treatment of non-small-cell lung cancer N Engl J Med 372 2018-2028 https://doi.org/10.1056/NEJMoa1501824 PMID: 25891174

85. Gaule P, Smithy JW, and Toki M, et al (2017) A quantitative comparison of antibodies to programmed cell death 1 ligand 1 JAMA Oncol 3256 https://doi.org/10.1001/jamaoncol.2016.3015

86. Rimm DL, Han G, and Taube JM, et al (2017) A prospective, multi-institutional, pathologist-based assessment of 4 immunohistochemistry assays for PD-L1 expression in non-small cell lung cancer JAMA Oncol 3(8) 1051-1058 https://doi.org/10.1001/ jamaoncol.2017.0013 PMID: $\underline{28278348}$ PMCID: $\underline{5650234}$

87. Rizvi NA, Hellmann MD, and Snyder A, et al (2015) Mutational landscape determines sensitivity to PD-1 blockade in non-small cell lung cancer Science 348 124-128 https://doi.org/10.1126/science.aaa1348 PMID: 25765070 PMCID: 4993154

88. Spigel DR, Schrock AB, and Fabrizio D, et al (2016) Total mutation burden (TMB) in lung cancer (LC) and relationship with response to PD-1/PD-L1 targeted therapies J Clin Oncol 349017

89. Thompson JC, Yee SS, and Troxel AB, et al (2016) Detection of therapeutically targetable driver and resistance mutations in lung cancer patients by next-generation sequencing of cell-free circulating tumor DNA Clin Cancer Res $225772-5782$ https:// doi.org/10.1158/1078-0432.CCR-16-1231 PMID: $\underline{27601595}$ PMCID: $\underline{5448134}$

90. Brahmer J, Horn L, and Jackman D, et al (2017) Five-year follow-up from the CA209-003 study of nivolumab in previously treated advanced non-small cell lung cancer (NSCLC): clinical characteristics of long-term survivors Cancer Res 77 CT077CT077 https://doi.org/10.1158/1538-7445.AM2017-CT077

91. Antonia SJ, Villegas A, and Daniel D, et al (2017) Durvalumab after chemoradiotherapy in stage III non-small-cell lung cancer $N$ Engl J Med NEJMoa1709937 https://doi.org/10.1056/NEJMoa1709937 